\title{
Affect Computation Models from Textual Aspect: A Brief Survey
}

\author{
Lata Gohil \\ Research Scholar, CHARUSAT \\ Changa, India-388 421 \\ Institute of Technology, \\ Nirma University, India-382 481
}

\author{
Dharmendra Patel, PhD \\ Smt. Chandaben Mohanbhai Patel Institute of \\ Computer Applications (CMPICA) \\ CHARUSAT, Changa, \\ India-388 421
}

\begin{abstract}
Human emotions are outcome of the subjective evaluation of events that occur in the environment. There are various affect theories in psychology to understand human emotion. To make Human-Computer-Interaction (HCI) intelligent, affect theory are to be incorporated. In this paper, discussion of various affect theories and affect computation models have been presented.
\end{abstract}

\section{General Terms}

Data mining, text mining, emotion detection, sentiment analysis

\section{Keywords}

Emotion detection from text, emotion detection approaches

\section{INTRODUCTION}

\subsection{Affect, Emotion and Mood}

Affect is a broad term that covers a wide range of feelings that people experience. It is a concept which comprises of emotion and mood [1]. Emotions are intense feelings that are directed at someone or something [2]. Emotions are reaction to a person or event and these intense feelings comes and goes quickly i. e. last for few minutes or seconds. Moods are feelings that tend to be less intense compared to emotions and often having absence of contextual stimulus [3]. Emotions are short-lived than moods. Moods last for hours or days. Cause for mood is often general and unclear. Unlike moods, emotions tend to be discovered with facial expressions. Some researchers speculate that emotions may be action-oriented while moods may be cognitive in nature [4]. Strong and deep emotions can turn into moods after losing focus on caused event or object. Mood in turn makes more emotional in response to an event. Thus, emotions and moods can mutually influence each other.

There are numerous emotions include anger, contempt, enthusiasm, envy, fear, frustration, disappointment, embarrassment, disgust, happiness, hate, hope, jealousy, joy, love, pride, surprise, and sadness. There have been various research efforts to limit and define emotions into a fundamental or basic set of Emotions [5]. There are six basic emotions: anger, fear, sadness, happiness, disgust, and surprise, other emotions are included in one of these six categories [6]. Grouping emotions into positive and negative categories becomes mood states as it represents more general emotions instead of isolating one particular emotion. There are two dimensions of mood: positive affect and negative affect. Researchers have labeled mood dimensions as a positive affect and negative affect instead of labeling positive mood or negative mood.

\subsection{Affective Computing}

Affective computing [8] is "computing that relates to, arises from, or deliberately influences emotions". Picard states that computers require the ability to (at least) recognize and express affect to gain natural and intelligent interaction with humans [8]. If it is required that computers are human like intelligent and interact naturally with users, computers must have the ability to recognize, understand, and even to have and express emotions.

For a long time, the field of computing and information processing has only dealt with data information but sentiment information has not taken into consideration as sentiment has been cast as the opposite of intelligence. A conversation lacking of sentiment cannot achieve the desire effect. Thus, information without sentiment is not complete.

Human beings do have strong experiences regarding sentiment in their life. For example, the same dialog exhibit different meaning to different people in different environments. Sentiment understanding and processing is crucial in intelligence science and technology. The current technology is able to convert "data" to "information" and "information" to "knowledge"; it is on pathway to convert "knowledge" to "intelligence".

An essential goal [10] of Affective Computing is to design a computer system that responds in a rational and strategic way to real-time changes in user affect, cognition, and motivation, as represented by speech, facial expressions, neurocognitive performance, physiological signals, multimodal combination etc.

Because emotions include both intra-personal uncertainty (the uncertainty a person has about an emotion), and inter-personal uncertainty (which results from the fact that different people have different perceptions and expressions of the same emotion), it is promising to use fuzzy logic systems [12].

Emotions play a key role in judging the use of products [13]; for example one will feel great using a product that is not user friendly, but pleasing to the eye. There are other factors which play a role in user experience. A photo camera with a "smile shutter" was introduced by Sony Company in 2007 which recognize smile on the person in focus [14]. But there is requirement of intelligent systems which can recognize happiness. In the field of affective computing, intelligent systems are being designed to recognize, interpret, and process emotions $[15,1]$.

The ability to detect and influence affective states in others is significant in human communication and will be required for machines to interact effectively with humans [1]. As per [16], emotional reactions in humans become more central, more 
controlled and less physical, as part of the process of growing up and becoming emotionally mature.

According to [17], the most natural mode of expression in humans is language. The language can convey rich information about mental states by making thought processes "readable" externally which allows richer and diverse affective states to be expressed. The written communication is more powerful to express affective states than either a set of verbal labels or a set of physiological patterns.

The recent scientific findings show that emotions play a vital role in rational decision-making, perception, learning, and various cognitive tasks [18].Therefore, endowing machines with a degree of emotional intelligence leads to more meaningful and natural human-machine interaction. If machines understand a person's affective state, humanmachine interaction may become smoother, more intuitive, and more efficient [19][20].

\section{AFFECT THEORY}

In psychology theory of affect, concepts have been defined at abstract level using natural language description and this informal description having implicit assumptions and hidden complexities. Since the affective state of humans is subjective experience it is difficult to find objective definition. That is why there are number of approaches in psychology literature to model affect.

\subsection{Categorical Models}

Categorical representations use a word to describe an emotional state. Such category groups have been proposed on different grounds such as application-specific emotion sets, most frequent everyday emotions, evolutionarily basic emotion categories etc. In this model, Emotions are organized in hierarchy of basic elements and sub-elements. There is no common agreement on basic emotions as they may vary in number and nature. Despite the lack of agreement, many authors consensus on six emotions [21]: joy, surprise, fear, anger, sadness and disgust. Complex emotions can then be defined as combination of these basic emotions, e.g contempt as a mix of anger and disgust [22].

\subsection{Dimension Models}

Dimensional theories conceptualizes affective phenomena as points in a continuous (usually two or three) dimensional space. Many computational dimensional models build on the three-dimensional model of Mehrabian and Russell (1974)[23] and these dimensions correspond to pleasure, arousal and dominance where pleasure measures valence; arousal indicates the level of affective activation and dominance measures power or control. Using additional dimensions such as approach/avoidance leads to more refinement. Dimensional representations allow describing affective states more tractable than using words and also good at dealing with non-discrete emotions.

Affect Control Theory (ACT) which was initially introduced by Osgood [24] is dimensional model which has gain attention of researchers for affect modeling. This theory is based on the conviction that the affective meaning of word or concept can be measured and expressed in terms of three dimensions namely evaluation (positive vs. negative), potency(strong vs. week) and activity(lively vs. quiet). The study of the affective meaning of words or concepts has been key aspect of ACT research. This theory hypothesizes that there are certain cultural norms that dictate the affective meanings of words, norms that people in a culture with a common language share [25]. Each words having fundamental affective meaning and people adjust this meaning according to the context in which words are used.

\subsection{Appraisal Models}

Appraisal theories focus on the affect elicitation process. Appraisal representations characterize affective states in terms of the detailed evaluations of eliciting conditions. According to this model affect arises from two basic processes: appraisal and coping. Appraisal process is informed by cognitive processes involved in understanding and interacting with environment. Through appraisal person assesses his or her relationship with environment. The person-environment relationship expresses using set of common terms called appraisal variables which are often measurable and tractable. Coping process determines how person responds to the appraised significance of events. Person is motivated to respond to events differently depending on how they are appraised [26].Human coping responses are categories into two classes: problem-focused coping approach attempt to change the environment; emotion-focused coping [27] involves inner-directed strategies to deal with emotions.

As Appraisal theories structure makes it feasible for simulating their hypotheses in computational models, they are commonly used in affect modeling. Appraisal theory was adopted by several psychology researchers as a hypothesis for emotion modeling.

The computationally tractable attribute of the OCC model proposed by Ortony et al. [28] was utilized as the basis for developing a number of computational models for affective processes by numerous researchers in the field of affective computing. The OCC model has the ability to understand affects, reason about them and express them.

\subsection{Plutchik model}

Plutchik[11] model is based on psycho evolutionary theory of emotion. This model proposed eight primary emotions: joy, trust, fear, surprise, sadness, anticipation, anger, and disgust; while other emotions are represented as mixture of these basic emotions. The mixture of any two primary emotions is called dyad. There are three dyads: primary, secondary and tertiary. Each primary emotion has opposite primary emotion. This model visually represented as color of wheel where color denotes intensity of emotion. Color is darker towards center of wheel so as increase the intensity of emotion while lighter on opposite side so as to decrease the intensity.

\section{AFFECT COMPUTATION MODELS}

Affect modeling is the process of transforming informal theories of affect into concrete and tractable processes that are essential mechanisms in any computational architecture. The qualitative nature of the emotion theories does not address some key elements such as intensity and duration of an emotional experience that are essential for most of affectenabled applications and hence building quantitative models for affect is challenging task. Thus, affect computation model extends the scope of the theory by addressing the hidden and detail assumption of affect theory.

The computational models of affect are implemented in intelligent agents of various domains. For example in the field of robotics and in the computer gaming industry, large number of affect-enabled applications has been built based on these computational models. These computational models are important for improving the performance of HumanComputer Interaction (HCI) applications in order to develop 
intelligent virtual agents that exhibit a maximal degree of human-like affective behavior [29]. For building affect computational models, various affect theory approaches such as appraisal, dimensional, adaptation and coping have been used by researchers.

The Emotion and Adaptation (EMA) [30] is a computational model of emotions based on appraisal theory in which agentenvironment relationships are represented using causal rules and these rules interpret the emotion elicitation dynamics as well as different adaptation and coping strategies. There are two types of causal interpretation in which cognitive process is slow and deliberative while other one is fast and reactive. EMA adopts the emotion theory proposed by Lazarus[31] to build computation model of coping (i. e. the regulation of negative emotion. In this model, past events, current state, possible future world states as well as belief, desires and intentions are key role players in the emotional process.

A Layered Model of Affect (ALMA) [32] is an OCC [28] based model. In this model three major affective characteristics are integrated in a three-dimensional space: emotion as short-term, mood as medium-term and personality as long-term. ALMA adopts the approach of Mehrabian [7]. The mood state of the agent is defined based on the classification of each of the three mood dimensions pleasure $(\mathrm{P})$, arousal (A) and dominance (D). These three discrete components build the so called PAD space and each point of this space represents a mood state called mood octant. ALMA uses a mapping between OCC emotions to the PAD components of the mood octant to calculate the overall mood state of the agent and this measure is widely used in the calculations of emotion intensity levels.

ElNasr et al. [34] proposed fuzzy logic based computation model of emotion called FLAME. This OCC-inspired appraisal model uses fuzzy logic rules to map the appraisals of events impact on goals into emotional intensities [34]. This model includes several learning and coping algorithms to be used for the purpose of adaptation performed by the agent in response to the changes of some aspects of the environment.

\section{DETECTING AFFECT FROM TEXT}

Affect detection in text targets to understand the underlying emotions. The approaches for detecting emotions from text are keyword based (make use of keywords present in text and emotion dictionaries), learning based (use machine learning algorithms) or hybrid based approaches (combination of keyword based approach and learning based approach). Text based affect detection can be used in various fields such as education, business, social communication, psychology where there is supreme need to understand and interpret emotions in text.

Shaheen et al. [34] presented framework for recognizing the six emotions proposed by Ekman: happiness, sadness, anger, fear, disgust and surprise [33] in English sentence. By considering emotions in sentence as generalized concept is extracted using syntactic and semantic structure of sentence. The generalized representation of extracted concepts is prepared using ontologies such as WordNet and ConceptNet called emotion recognition rule (ERR). The annotated ERRs prepared which are used against comparing ERR of input sentence using classifier-suite (k-nearest neighbors, Point Mutual Information, Point Mutual Information with Information Retrieval). The resultant performance of this approach is an average F-score of $84 \%$.
Alhothali et al. [35] proposed approach uses Affect Control Theory (ACT) to assign different emotions towards factual (objective) content and towards its entities (subject and object). The ACT lexicon was augmented using a label propagation algorithm. The emotions predicted are coarsegrained emotions: positive and negative. The emotions for news headline corpus is predicted using the augmented lexicon and ACT equations which resulted into a precision of $82 \%, 79 \%$, and $68 \%$ towards the event, the subject, and object, respectively.

Shaikh et al. [36] approach is based on OCC emotion model which derives 22 emotions. It relates cognitive variables of the OCC emotion model to linguistic components in text. This linguistics-based rule set based approach achieved $80.5 \%$ accuracy.

Huangfu et al. [37] proposed approach uses a statistical method to extract emotion lexicon with their dimension values from texts. The rule-base set is prepared for emotions: joy, distress, hope, fear, pride, shame; using OCC emotion model. The study on security-related news reviews corpora performs well and gives reasonably good result.

Suttles et al. [38] approach uses Plutchik's set of four pairs of opposing emotions for developing binary emotion classifiers for Twitter data using features includes hashtag, emoticons and emoji. The multi-class problem of emotion classification is considered as a binary problem for four opposing emotion pairs. That best performing classifiers yield accuracy between $75-91 \%$.

Table 1. Affect Detection approaches

\begin{tabular}{|c|c|c|c|c|}
\hline $\begin{array}{l}\text { Pape } \\
\text { rs/ } \\
\text { Stud } \\
\text { y }\end{array}$ & $\begin{array}{l}\text { Emotion } \\
\text { Model }\end{array}$ & $\begin{array}{l}\text { Emotion } \\
\text { Categories }\end{array}$ & $\begin{array}{l}\text { Approac } \\
\text { h Used }\end{array}$ & $\begin{array}{l}\text { Applied } \\
\text { to/Datas } \\
\text { et } \\
\text { /Corpor } \\
\text { a }\end{array}$ \\
\hline [34] & $\begin{array}{l}\text { Categorica } \\
1 \text { (Ekman) }\end{array}$ & $\begin{array}{l}\text { Happiness, } \\
\text { Sadness, } \\
\text { Disgust, } \\
\text { Anger, } \\
\text { Surprise, } \\
\text { Fear }\end{array}$ & $\begin{array}{l}\text { Lexical- } \\
\text { based, } \\
\text { Machine } \\
\text { Learning } \\
\text { Algorith } \\
\text { ms }\end{array}$ & $\begin{array}{l}\text { Written } \\
\text { commu } \\
\text { nication } \\
\text { in } \\
\text { English } \\
\text { Langua } \\
\text { ge }\end{array}$ \\
\hline [35] & $\begin{array}{l}\text { Dimension } \\
\text { al (ACT) }\end{array}$ & $\begin{array}{l}\text { Positive, } \\
\text { Negative }\end{array}$ & $\begin{array}{l}\text { Lexical- } \\
\text { based }\end{array}$ & $\begin{array}{l}\text { News } \\
\text { Headlin } \\
\text { es }\end{array}$ \\
\hline [36] & $\begin{array}{l}\text { Appraisal } \\
\text { (OCC) }\end{array}$ & $\begin{array}{l}\text { Joy, } \\
\text { Distress, } \\
\text { Happy-for, } \\
\text { Sorry-for, } \\
\text { Resentment, } \\
\text { Gloating, } \\
\text { Hope, Fear, } \\
\text { Satisfaction, } \\
\text { Fears- } \\
\text { confirmed, } \\
\text { Relief, } \\
\text { Disappointm } \\
\text { ent, Shock, } \\
\text { Surprise, } \\
\text { Pride, } \\
\text { Shame, } \\
\text { Admiration, } \\
\text { Reproach, } \\
\text { Gratification } \\
\text {, Remorse, }\end{array}$ & $\begin{array}{l}\text { Rule- } \\
\text { based }\end{array}$ & $\begin{array}{l}\text { English } \\
\text { sentence } \\
\text { s } \\
\text { includes } \\
\text { reviews } \\
\text { of } \\
\text { products } \\
\text { movies, } \\
\text { news, } \\
\text { and } \\
\text { email } \\
\text { correspo } \\
\text { ndence }\end{array}$ \\
\hline
\end{tabular}




\begin{tabular}{|l|l|l|l|l|}
\hline & & $\begin{array}{l}\text { Gratitude, } \\
\text { Anger, } \\
\text { Love, Hate }\end{array}$ & & \\
\hline$[37]$ & $\begin{array}{l}\text { Appraisal } \\
\text { (OCC) }\end{array}$ & $\begin{array}{l}\text { joy, distress, } \\
\text { hope, fear, } \\
\text { pride, shame }\end{array}$ & $\begin{array}{l}\text { Rule- } \\
\text { based }\end{array}$ & $\begin{array}{l}\text { online } \\
\text { data } \\
\text { from } \\
\text { security } \\
\text { domain }\end{array}$ \\
\hline$[38]$ & $\begin{array}{l}\text { Plutchik's } \\
\text { "wheel of } \\
\text { emotions" }\end{array}$ & $\begin{array}{l}\text { Anger, } \\
\text { Disgust, } \\
\text { Fear, } \\
\text { Happiness, } \\
\text { Sadness, } \\
\text { Surprise, } \\
\text { Trust, } \\
\text { Anticipation }\end{array}$ & $\begin{array}{l}\text { Supervis } \\
\text { ed } \\
\text { Learning } \\
\text { Algorith } \\
\text { m }\end{array}$ & Tweets \\
& & & \\
\hline
\end{tabular}

The table 1 is the compilation of paper reviewed for the survey which has utilized different emotion models, emotion categories, approaches and corpora.

\section{CONCLUSION}

Intelligence can be incorporated in HCI using affective computation. This paper is a brief discussion of various affect theories in psychology and their transformation in computational process. The affect theories have hidden complexities as these theories are at abstract level and therefore incorporating them into computational process is difficult task. Various affect computation models have been discussed in this paper which has been applied to different domain. Affect detection from text employs different emotion models and approaches for coarse-grained and fine-grained emotion recognitions. Very less work has been reported on fine grained emotion detection using ACT. The growing amount of multilingual corpus data on web requires increased use of multilingual affect analysis which should include more non English languages and dialect variation also.

\section{REFERENCES}

[1] J. M. George, "Trait and State Affect," in K. R. Murphy (ed.), Individual Differences and Behavior in Organizations (SanFrancisco: Jossey-Bass, 1996), p. 145.

[2] N. H. Frijda, "Moods, Emotion Episodes and Emotions," in M. Lewis and J. M. Haviland (eds.), Handbook of Emotions (New York: Guilford Press, 1993), pp. 81-403.

[3] H. M. Weiss and R. Cropanzano, "Affective Events Theory:A Theoretical Discussion of the Structure, Causes and Consequences of Affective Experiences at Work," in B. M. Staw and L. L. Cummings (eds.), Research in Organizational Behavior, vol. 18 (Greenwich, CT: JAI Press, 1996),pp. 17-19.

[4] Ekman and Davidson (eds.), The Nature of Emotions: Fundamental Question.

[5] P. Shaver, J. Schwartz, D. Kirson, and C. O'Connor, "Emotion Knowledge: Further Exploration of a Prototype Approach," Journal of Personality and Social Psychology, June 1987, pp. 1061-86; P. Ekman, "An Argument for Basic Emotions," Cognition and Emotion, May/July 1992, pp. 169-200;C. E. Izard, "Basic Emotions, Relations among Emotions, and EmotionCognition Relations," Psychological Bulletin, November 1992, pp. 561-65; and R. Plutchik, The Psychology and Biology of Emotion (New York: HarperCollins, 1994).
[6] Weiss and Cropanzano, "Affective Events Theory," pp. 20-22.

[7] A. Mehrabian, "Pleasure-arousal-dominance: A general framework for describingand measuring individual differences in temperament."

[8] R. Picard, Affective Computing. Cambridge, MA: The MIT Press, 1997.

[9] M. S. El Nasr and J. Yen, "Flame: Fuzzy logic adaptive model of emotions," Autonomous Agents and MultiAgent Systems, vol. 3(3), pp. 219_257, 2000

[10] N. Serbedzija and S. Fairclough, "Biocybernetic loop: From awareness to evolution," in Proc. IEEE Congress on Evolutionary Computation,Trondheim, Norway, May 2009, pp. 2063-2069.

[11] Plutchik R. "The psychology and biology of emotion", New York: Harper Collins, 1994.

[12] D. Wu, "Fuzzy sets and systems in building closed-loop affective computing systems for human-computer interaction: Advances and new directions," IEEE World Congress on Computational Intelligence, Brisbane, Australia, June 2012.

[13] Norman, D.A.: Emotional Design: Why we Love (or Hate) Everyday Things. Basic Books,New York (2004)

[14] Sony, http://news.sel.sony.com/en/press_room/consumer/digita 1_imaging/digital_ shot/release/31103.html cameras/cyber-

[15] Boehner, K., DePaula, R., Dourish, P., Sengers, P.: How Emotion is Made and Measured. International Journal of Human-Computer Studies 65(4), 275-291 (2007)

[16] Daniel Goleman. Emotional Intelligence: Why It Can Matter More than IQ. Bloomsbury Publishing, London, 1996.

[17] Affective Computing, Aaron Sloman, reviewer; AI Magazine, Spring 1999, pp. 127-137

[18] A. R. Damasio, Descartes' error, Grosset/Putnam, New York, 1994.

[19] H. Simon, "Motivational and Emotional Controls of Cognition," Models of Thought, pp. 29-38, Yale University Press, 1979.

[20] A. Sloman and M. Croucher, "Why Robots will Have Emotions," Proc. of the SeventhInternational Conference on Artificial Intelligence, pp. 197-202, 1981.

[21] Cornelius, R. The Science of Emotion: Research and Tradition in the Psychology of Emotion. New Jersey: Prentice-Hall, 1995.

[22] Plutchik, R. The emotions. University Press of America, 1990.

[23] MEHRABIAN, A. \& RUSSELL, J. A. (1974) An Approach to Environmental Psychology, Cambridge, Mass, The MIT Press.

[24] C. E. Osgood, "Studies of the generality of affective meaning systems," American Psychologist, vol. 17, pp. $10 \_28,1962$. 
[25] Dawn T. Robinson and Lynn Smith-Lovin. Contemporary Social Psychological Theories, chapter Affect Control Theory. Stanford Social Sciences, 2006.

[26] E. Peacock and P. Wong, "The stress appraisal measure (SAM): A multidimensional approach to cognitive appraisal,"Stress Medicine, vol. 6, pp. 227-236, 1990.

[27] R. Lazarus, Emotion and Adaptation. NY: Oxford University Press, 1991.

[28] A. Ortony, G. Clore, and A. Collins, The Cognitive Structure of Emotions.Cambridge University Press, 1988.

[29] P. M. T. J. Bosse, T., "A computational model based on gross emotion regulation theory," Cognitive systems research, vol. 11, pp. 211_230, 2010.

[30] G. J. Marsella, S. and P. Petta, Computational Models of Emotion, for Affective Computing. ict.usc.edu, 2010.

[31] R. S. Lazarus, "Progress on a cognitive-motivationalrelational theory of emotion." American Psychologist, vol. 46(8), pp.819_834, 1991.

[32] P. Gebhard, "Alma - a layered model of affect," in Fourth International Joint Conference on Autonomous Agents and Multiagent Systems, 2005.

[33] P. Ekman, (1999) Basic emotions. In T. Dalgleish and T. Power (Eds.) The handbook of cognition and emotion. Pp. 45-60. New York.: John Wiley \& Sons.
[34] S. Shaheen, W. El-Hajj, H. Hajj and S. Elbassuoni, "Emotion recognition from text based on automatically generated rules", Proceedings of IEEE International Conference on Data Mining

[35] A. Alhothali, J. Hoey, "Good news or bad news: using affect control theory to analyze readers' reaction towards news articles, in", Proceedings of the 2015 Conference of the North American Chapter of the Association for Computational Linguistics: Human Language Technologies, Association for Computational Linguistics, Denver, Colorado, 2015, pp. 1548-1558.

[36] Shaikh, M.A.M., Prendinger, H. and Ishizuka, M. (2009). "A Linguistic Interpretation of the OCC Emotion Model for Affect Sensing from Text", Affective Information Processing, Springer London, 45-73

[37] L. Huangfu, W. Mao, D. Zeng and L. Wang, "OCC model-based emotion extraction from online reviews," Intelligence and Security Informatics (ISI), 2013 IEEE International Conference on, Seattle, WA, 2013, pp. 116121.

[38] J. Suttles and N. Ide. Distant supervision for emotion classification with discrete binary values. In Computational Linguistics and Intelligent Text Processing, pages 121-136. Springer, 2013. 